\title{
Oral habits and open bite among children aged 8-12 years in Kinondoni, Dar es Salaam, Tanzania
}

\author{
Kikwete $\mathrm{S}^{1}$, Kahabuka FK ${ }^{2}$ \\ 1 Muhimbili National Hospital \\ 2 School of Dentistry, Muhimbili University of Health and Allied Sciences (MUHAS) P.O. Box 65014, Dar es \\ Salaam, Tanzania
}

Kikwete S, Kahabuka FK

Oral habits and open bite among children aged 8-12 years in Kinondoni, Dar es Salaam, Tanzania. Tanz Dent J 2009; 15 (2):37-41

\begin{abstract}
:
Aim: To determine the prevalence of oral habits and their relationship with the occurrence of open bite among 8 to 12 years old children in Kinondoni District, Dar es Salaam. Study design: A cross sectional study. Subjects and methods: All children aged 8-12 years from four government primary schools were eligible to participate. Using school registers, twenty children of each age were randomly selected giving a total of 100 children from each school. Face to face interviews were conducted using a structured questionnaire. The questionnaire inquired about oral habits of the children including thumb sucking, tongue thrusting, lip sucking, nail biting and/or mouth breathing. Children were also examined clinically for the presence of open bite. Results: A total of 394 primary school children participated. Females constituted $52.5 \%$ of the study sample. Nail biting was the most frequently practiced habit $(53.3 \%)$, followed by lip sucking (13.7\%), tongue thrusting (11.9\%), thumb sucking $(9.4 \%)$ and finger sucking $(5.1 \%)$. Mouth breathing was the least practiced oral habit. Forty six children $(11.7 \%)$ had an open bite. Tongue thrusting was significantly associated with age being seen more $(14.8 \%, \mathrm{P}=0.026)$ in the younger age group 8-10 years. Open bite was significantly more prevalent among thumb $(\mathrm{P}=0.01)$ and finger $(\mathrm{P}=0.001)$ suckers than non suckers. Conclusion: The most common oral habits in this age group were nail biting, lip sucking and tongue thrusting. Open bite was more prevalent among thumb and finger suckers than non suckers.
\end{abstract}

Key words: Oral habits, open bite, school children, Tanzania

Correspondence: Kahabuka F.K, School of Dentistry, P.O. Box 65014, Dar es Salaam, Tanzania. Tel:+255-22-2151135 or +255-22-2150564, Cell: +255-754-538084,

Fax: +255-22-2150465, e-mail: fkahabuka@muhas.ac.tz

\section{Introduction}

An oral habit is any repetitive behavior pattern which utilizes the oral cavity (1). The oral habit arises from a reflex seen in infancy (1-3). Generally, the longer the habit is practiced the harder it will be to break it, and the more are the long term problems seen in the oral cavity $(1,3)$.

During infancy, the sucking mechanism is the most well developed sensation as it helps to sustain as well as to derive sensory pleasure and to give to the child a feeling of security, warmth and euphoria (1). Therefore, an impatiently nursed baby looses the warmth and feeling of well being and is therefore deprived of the sucking pleasures (1). This deprivation may motivate the infant to suck a thumb or finger for additional gratification, known as non-nutritive sucking $(1,3)$.

Non nutritive sucking habits include, pacifier use, finger sucking habits, nail biting and tongue thrusting. Other oral habits are, lip sucking, mouth breathing, bruxism, self mutilation habit and pencil/pen biting (4). Of these oral habits, Thumb sucking is the earliest and the most common of these habits among young children (2-3). Although almost all children engage in non nutritive sucking, most children do give up the habit by the age of 4-5 years. Moreover, half of the children with a finger sucking habit will still retain the habit by the age of 7 years (5-6).

Onyeaso (7) reported that $9.9 \%$ of Nigerian children had oral habits; of which $8.1 \%, 1.2 \%$, and $0.2 \%$ had digit sucking, lip sucking and fore arm sucking habits respectively. In India however, Kharbanda et al. (8) reported a higher oral habits prevalence of $25.5 \%$ among school going children. Tongue thrust was the most prevalent habit practiced by $18.1 \%$ of the children followed by mouth breathing $(6.6 \%)$, thumb sucking $(0.7 \%)$ and lip biting $(0.04 \%)$. Previous studies have reported the prevalence of finger sucking to range from 3 $96 \%(5,9-10)$. 
Regarding sex, digit sucking, tongue thrust, mouth breathing and bruxism have been found to be more prevalent among boys. On the other hand, lip/cheek biting, nail and pencil biting have been found to be more in girls, (10).

A prolonged oral habit after seven years of age, can lead to malocclusion. Depending on the frequency, length, and intensity of sucking malocclusion may persist into mixed dentition (2-3, 11). Malocclusions that may occur as a result of prolonged oral habits include; reduced vertical growth of the frontal parts of the alveolar process which creates an anterior open bite, protrusion and proclination of the maxillary incisors as a result of horizontal force created by the digit, and lengthening of the maxillary incisors arch (maxillary arch constriction). Other malocclusions are; anterior displacement of the maxilla, unilateral and bilateral post normal molar relationship, proclination or retroclination of the lower incisors, which may be due to the strength of muscles of the lips and tongue activity during sucking. Depending on the degree of the malocclusion, orthodontic intervention may be required $(8,12)$. Other malocclusions that may occur due to other oral habits

Orthodontic treatment is expensive and takes a lot of time for both patient and practitioner. Hence it is plausible to put preventive measures in place which necessitates availability of information regarding the prevalence of oral habits and their effects. No information about the prevalence and possible effects of oral habits among Tanzanian children could be retrieved. Therefore, the aim of this study was to determine the prevalence of oral habits and their relationship with an open bite among primary school children aged 8-12 years in Kinondoni District, Dar es Salaam.

\section{Methodology}

A cross sectional study was conducted in Kinondoni municipality, Dar es Salaam. Four schools were conveniently chosen from a list of Kinondoni government primary schools. The sample size was pre-determined to be 384 through calculation by means of the single proportion formula by Leslie used in the stat calculator programme of EPI-Info. All children aged 8-12 years at the chosen schools were eligible to participate. Using school registers, twenty children of each age were randomly selected giving a total of 100 children from each school. Overall, 400 children were selected.

Face to face interview, observation and clinical examination were employed in data collection. The interview utilized a structured questionnaire and inquired whether children had the following oral habits, thumb sucking, finger sucking, tongue thrusting, lip sucking, nail biting and mouth breathing. Since children were not aware of their bruxism, this habit was not investigated. To confirm for tongue thrusting, lip sucking and mouth breathing habits, all children were observed for two minutes when at rest without their awareness. Tongue thrusting was scored as present if a child was seen positioning his/her tongue between the teeth moving it forth and back like a sucking movement. Lip sucking was scored as present if the child was seen sucking his/her lower or upper lip at rest. Mouth breathing was scored as present if the child was observed breathing through the mouth, often leaving the mouth slightly open when at rest. All children were clinically examined for the presence of an open bite, when molars were in occlusion.

Data analysis was carried out using the Statistical Package for Social Sciences (SPSS version 10.0). Frequency tables were generated. Cross tabulations were done between oral habits and age, sex or an open bite. Chi-square test was used to test for significant differences. P-value $<0.05$ was chosen as a level of significance.

Ethical clearance was obtained from MUHAS ethical committee. All the information obtained from study participants was kept confidential.

\section{Results}

A total of 394 children participated in the study of whom $47.5 \%$ were boys and $52.5 \%$ were girls. The younger age group aged 8-10 years were slightly more $(53 \%)$ than the elder children aged 11 to 12 years (Table 1).

Table 1: Age and sex distribution of the study participants

\begin{tabular}{lllllll}
\hline & \multicolumn{4}{c}{ Sex } & \multicolumn{2}{c}{ Total } \\
\cline { 2 - 8 } \multicolumn{1}{c}{ Age } & \multicolumn{2}{c}{ Male } & \multicolumn{2}{c}{ Female } & no & \% \\
\cline { 2 - 8 } & $\mathrm{n}$ & $\%$ & $\mathrm{n}$ & $\%$ & & \\
\hline 8-10 years & 93 & 44.5 & 116 & 55.5 & 209 & 53 \\
$11-12$ years & 94 & 50.8 & 91 & 49.2 & 185 & 47 \\
\hline Total & 187 & 47.5 & 207 & 52.5 & 394 & 100 \\
\hline
\end{tabular}


Six oral habits (nail biting, lip sucking, tongue thrusting, thumb sucking, finger sucking, mouth breathing) were observed. Nail biting was the most practiced habit by $53.3 \%$ and the least practiced habit was mouth breathing by $0.3 \%$, (Table 2 ).

Table 2: Distribution of 394 study participants with various oral habits

\begin{tabular}{lcc}
\hline Oral habits & Frequency & Percentage (\%) \\
\hline Nail biting & 210 & 53.3 \\
Lip sucking & 54 & 13.7 \\
Tongue thrusting & 45 & 11.4 \\
Thumb sucking & 37 & 9.4 \\
Finger sucking & 20 & 5.1 \\
Mouth breathing & 1 & 0.3 \\
\hline
\end{tabular}

Table 3 presents the association of oral habits with age and sex. A higher proportion of children in the younger age group were tongue thrusters $(\mathrm{P}=$ 0.026 ) and no any other significant association was observed between age and other oral habits. Likewise, sex showed no significant association with any of the oral habits.

About $11 \%$ of the children aged 8-10 years and $11.4 \%$ of the $11-12$ year olds had open bite. More males $(16.6 \%)$ had an open bite than females (7.2\%). Twenty seven percent of children with thumb sucking habit had an open bite, while $10 \%$ of the children who did not suck their thumb had an open bite. Forty percent of the children who sucked their fingers had an open bite compared to $10 \%$ of the children who did not suck their fingers. Regarding nail biting, a similar proportion of the children $(11 \%)$ with and without the habits had an open bite. Eighteen percent of the children who were thrusting their tongue had an open bite compared to $11 \%$ with no tongue thrusting habit. An open bite was seen in $13 \%$ of the children who had lip biting habit compared to $11 \%$ of those without lip biting habit, (Table 4).

Table 3: Prevalence of oral habits by age and sex

\begin{tabular}{lcccccc}
\hline \multirow{2}{*}{ Oral habits } & $8-10$ & $11-12$ & P-value & Male & Female & P-value \\
\cline { 2 - 7 } Nail biting & $51.2 \%$ & $55.7 \%$ & NS & $48.7 \%$ & $57.5 \%$ & NS \\
Tongue thrusting & $14.8 \%$ & $7.6 \%$ & 0.026 & $10.7 \%$ & $12.0 \%$ & NS \\
Thumb sucking & $9.6 \%$ & $9.2 \%$ & NS & $10.2 \%$ & $8.7 \%$ & NS \\
Finger sucking & $5.7 \%$ & $4.3 \%$ & NS & $5.9 \%$ & $4.3 \%$ & NS \\
Lip sucking & $12.4 \%$ & $15 \%$ & NS & $11.8 \%$ & $14.0 \%$ & NS \\
Mouth breathing & $0.4 \%$ & $0 \%$ & NS & $0.5 \%$ & $0 \%$ & NS \\
\hline \multicolumn{7}{c}{ Key: NS = Not Significant }
\end{tabular}

Significantly higher proportion of boys $(\mathrm{P}=0.001)$, finger suckers $(\mathrm{P}=0.001)$ and thumb suckers $(\mathrm{P}=$ 0.01 ) had open bite. There was no significant association between an open bite and age, nail biting, lip sucking, or tongue thrusting.

\section{Discussion}

Some children were shy to admit their oral habits probably due to ridicule associated with being teased by their peers and family members. Perhaps the methodology used did not allow capturing of all children who had one or more oral habits. Notwithstanding we are of the opinion that those who gave information on their oral habits stand for the majority of the children with oral habits in this study group. Our findings however, may not be generalized for the whole Tanzanian child population.
Nail biting was the most prevalent $(53.3 \%)$ oral habit in the current study, this finding is similar to that by Alexander (13) in a study among Canadian children. However, our findings do not compare with the findings by Quashie-Williams et al (14). Children in this age range of 7 to 12 years are on the phase of learning to control their emotions. Emotional disturbances such as lack of love and care with too much fear and anxiety is a factor to nail biting (15). The proportions of thumb (9.4\%) and finger sucking $(5.1 \%)$ found in the current study are similar to those reported by Onyeaso (7). However, they are lower than those reported earlier by Farsi \& Salama (9) and Shetty \& Munshi (10). The lower prevalence of digit sucking in older children observed in this study is a known phenomenon. For instance, Bishara et al. (16) demonstrated a decrease in digit sucking with age. 
Possibly, as the child grows older she/he becomes more aware of the society's negative attitudes towards oral habits. Therefore a child may either stop the finger sucking habit or replace it with another habit which gives similar satisfaction.
Apparently, some children in the current study were initially practicing thumb or finger sucking but due to influence from the society they changed to lip sucking.

Table 4: Prevalence of open bite by age, sex and reported and/or observed oral habits

\begin{tabular}{|c|c|c|c|}
\hline & & $\begin{array}{l}\text { Children with open } \\
\text { bite formation }\end{array}$ & P-value \\
\hline \multirow[t]{2}{*}{ Age } & $8-10$ years & $10.5 \%$ & N.S \\
\hline & $11-12$ years & $11.4 \%$ & \\
\hline \multirow[t]{2}{*}{ Sex } & Male & $16.6 \%$ & 0.001 \\
\hline & Female & $7.2 \%$ & \\
\hline \multirow[t]{2}{*}{ Thumb sucking } & Yes & $27 \%$ & 0.01 \\
\hline & No & $10 \%$ & \\
\hline \multirow{2}{*}{ Finger sucking } & Yes & $40 \%$ & 0.001 \\
\hline & No & $10 \%$ & \\
\hline \multirow[t]{2}{*}{ Nail biting } & Yes & $11.9 \%$ & N.S. \\
\hline & No & $11.4 \%$ & \\
\hline \multirow[t]{2}{*}{ Tongue thrusting } & Yes & $17.8 \%$ & N.S \\
\hline & No & $10.9 \%$ & \\
\hline \multirow[t]{2}{*}{ Lip sucking } & Yes & $13 \%$ & N.S. \\
\hline & No & $11.5 \%$ & \\
\hline
\end{tabular}

Key: N.S = Not Significant

Generally, there were no significant sex differences with various oral habits. This is similar to the findings by Kharbanda et al. (8), and Bosnjak et al. (17). Nevertheless, Shetty \& Munshi (10) reported some sex differences. Analysis of individual habits revealed that more girls $(57.5 \%)$ had a nail biting habit than boys $(48.7 \%)$. This could be due to girls having a lot of stress and nervousness during adolescence, thus they become emotionally destructed and consequently engage themselves into a nail biting habit. However, an earlier report (15) indicated that nail biting habit is more common in boys than in girls.

With the exception of tongue thrusting which was more prevalent in the age group $8-10(14.8 \%)$ as compared to age group 11-12 (7.6\%), other habits did not vary with age. This observation differs from that of Bishara et al (16) who observed in children in their first eight years of life that oral habits varied with age. Thumb and finger sucking was prevalent in young ones while nail biting dominated in the older children, (16).

The proportion of children found with open bite $(11 \%)$ is similar to that reported by Cozza et al (11). On the other hand, it is higher than that reported by Onyeaso (7), and lower than that reported among Brazilian children (18).

Significant association was found between an open bite and finger sucking and thumb sucking. These findings confirm earlier reports $(11,18)$, that prolonged sucking habits are significant risk factors for an open bite. Finger and thumb sucking are associated with an open bite due to the fact that during the sucking action, digits rest directly on the incisors thus prevents complete or continued eruption of the incisors. Also the digit applies a lot of pressure on the teeth (4). On the contrary, there was no significant association between an open bite and lip sucking, tongue thrusting and nail biting.

These habits do not cause great dental problems. Christensen et al. (4) classified them as benign habits, as far as dental effects are concerned.

It is known that if the oral habits are stopped early, self correction of malocclusions usually occur. Therefore, special intervention programs and preventive actions should be instituted especially in the younger age groups.

\section{Conclusion}

The most common oral habits in this study were nail biting, lip sucking and tongue thrusting. Moreover, finger and thumb sucking were significantly associated with an open bite.

\section{Recommendation}

We recommend education to the mothers on prevention of oral habits and/or the importance of seeking dental attention early to allow intervention and thus avoid the development of malocclusion. 


\section{Aknowledgement}

The study was funded by Ministry of Science, Technology and Higher Education through Muhimbili University of Health and Allied Sciences.

Our sincere thanks to the Kinondoni District Administrative Officers for granting us permission to conduct this study. Thanks to the Head teachers, teaching staff and school children for their kind cooperation and participation in this study.

\section{References}

1. www.columbia.edu/itc/hs/dental/d7710/clientedit/oral habits (accessed December 2008)

2. Garattins G. Crozzali P, Valsasina A: Role of prolonged sucking in the development of dento skeletal changes in the face. Review of literature. Mondo Ortod. 1990;15:539-60.

3. da Costa OO, Orenuga OO. Dentofacial anomalies related to the digit sucking. Afr J Med Sci.2002;3:239-42.

4. Christensen JR, Fields HW, Adair SM. Oral Habits in Pinkham J.R, Casammassimo P.S, Fields H.W, McTigue D.J, Nowak AJ. Pediatric Dentistry: Infancy through Adolescence, $4^{\text {th }}$ edition. Elsevier's Health Sciences. Philadelphia, 2005, Chapter 26, pp 431-9.

5. Larsson E, Dahlin KG. The prevalence and the etiology of the initial dummy- and fingersucking habit. Am J.Orthod. 1985;87:432-5.

6. Thilander B, Ronning O. Introduction to Orthodontics $2^{\text {nd }}$ ed. Lagerblads. Karishamn 1995; Pg 90-1.

7. Onyeaso CO: Oral habits among 7-10 year-old school children in Ibadan, Nigeria. East Afr Med J. 2004;81:16-21.

8. Kharbanda OP, Sidhu SS, Sundaram K, Shukla DK. Oral habits in school going children in Delhi: a prevalence study, J. Indian Soc. Pedod Prev Dent 2003;21:120-4.
9. Farsi NM, Salama FS. Sucking habits in Saudi children prevalence, contributing factors and effects on primary dentition. Pediatr Dent. 1997;19:28-33.

10. Shetty SR, Munshi AK: Oral habits in children a prevalence study. J. Indian Soc Pedod Prev Dent. 1998;16:61-6.

11. Cozza P, Baccetti T, Franchi L, Mucedero M, Polimeni A. Sucking habits and facial hyperdivergency as risk factors for anterior open bite in the mixed dentition. Am J Orthod Dentofacial Orthop 2005;128:517-9.

12. Larsson E: Artificial sucking habits: etiology, prevalence and effect on occlusion. Int $\mathrm{J}$ Orofacial mycology. 1994;20:10-21

13. Alexander KC, Lane MR. Nail biting. Clinical Pediatrics.1990; 29; 12:690-2.

14. Quashie-William R, Dacosta O.O, Isiekwe MC. The prevalence of oral habits among 4 to 15 year's old school children in Lagos. Nigerian Journal of Health and Biomedical Sciences. 2007;6:78-82.

15. www.thearticleinsiders.com. (accessed December 2008)

16. Bishara SE, Warren JJ, Broffitt B, Levy SM. Changes in the prevalence of nonnutrive sucking patterns in the first 8 years of life. Am J Orthod Dentofacial Orthop 2006;130:31-6

17. Bosnjak A, Vucicevic-Bores V, Miletic I, Bozic D, Vukelja M. Incidence of oral habits in children with mixed dentition. Journal Oral Rehabilitation. 2002;29:902-5.

18. Peres KG, Barros AJ, Peres MA, Victoria CG. Effects of breast feeding and sucking habits on malocclusion in a birth cohort study. Rev Saude Publica 2007;41:343-50 